\title{
Intervalo para o alojamento e níveis de lisina, em dietas baseadas no conceito de proteína ideal, sobre o desenvolvimento muscular e rendimento de carcaça de frangos de corte
}

\author{
Delayed placement and dietary lysine levels, on diets based in the ideal protein concept, on muscular \\ development and carcass yield of broiler chickens
}

\author{
José Rodrigo Galli Franco ${ }^{I}$ Alice Eiko Murakami ${ }^{I^{*}}$ Cristiane Regina do Amaral Duarte ${ }^{\mathrm{II}}$ \\ Jovanir Inês Müller Fernandes ${ }^{\mathrm{III}}$ Elis Regina de Moraes Garcia' ${ }^{\mathrm{IV}}$ Ivan Moreira ${ }^{\mathrm{II}}$
}

\section{RESUMO}

\begin{abstract}
Este trabalho objetivou estudar os efeitos do intervalo para o alojamento (IA) e de níveis de lisina digestível (LD) nas dietas iniciais sobre o desenvolvimento do músculo do peito e rendimento de carcaça de frangos de corte. Para tanto, 1.760 pintos de corte, machos, Cobb500, foram distribuídos aleatoriamente em oito grupos experimentais em arranjo fatorial $2 \times 4$ de 4 IAs $(12,24,36$ e 48h) e dois níveis de $L D(1,143$ e 1,267\%), com quatro repetições e 55 aves por unidade experimental. Met+Cys, Thr e Trp foram balanceados no conceito de proteína ideal. Não houve interação significativa entre $L D e$ IA sobre as variáveis avaliadas. Os maiores pesos do peito desossado e filé de peito aos 21 dias de idade e peso corporal aos 43 dias foram obtidos no nível de $1,143 \%$ de LD. O peso do peito desossado, peso do filé, diâmetro das fibras musculares aos 21 dias, peso vivo, peso da carcaça e peso das pernas aos 43 dias de idade decresceram linearmente de acordo com o aumento no intervalo para alojamento. Os resultados deste estudo sugerem que o nível de 1,143\% de LD favorece aumento no músculo peitoral aos 21dias e o peso vivo dos frangos aos 43 dias, e que o menor intervalo para o alojamento melhora o desenvolvimento dos músculos peitorais durante a fase inicial, $e$ maior rendimento da carcaça inteira e das pernas no abate.
\end{abstract}

Palavras-chave: células satélite, desenvolvimento muscular, filé de peito, jejum, relação proteína:DNA.

\section{ABSTRACT}

This study aimed to study the effects of delayed placement (IA) and dietary lysine levels $(L D)$ in initial diets on breast muscle development and carcass yield of broiler chickens. For this, 1,760 male Cobb500 chicks were allocated randomly to eight experimental groups according to a $2 \times 4$ factorial arrangement for 4 IAs (12, 24, 36 and 48h) and 2 levels of $L D$ (1.143 and $1.267 \%$ ) with four replicates and 55 chicks per experimental unit. Met+Cys, Thr and Trp were balanced according to the ideal protein concept. There were no significant interactions between $L D$ and IA on variables evaluated. The highest breast weight and breast fillet weight at 21 days old and body weight at 43 days old were obtained with the dietary lysine level of $1.143 \%$. The breast weight, breast fillet weight and muscle fiber diameter at 21 days old, body weight, carcass weight and legs weight at 43 days old decreased linearly according to the increase of the delayed placement. The results of this study suggest that the $1.143 \%$ DL level improves the breast muscle development at 21 days old and chicken body weight at 43 days old, and the shortest delayed placement improves the breast muscle development during the initial phase and higher carcass yield and legs at the slaughter.

Key words: breast fillet, muscle development, protein:DNA ratio, satellite cells, starvation.

\section{INTRODUÇÃO}

Nos últimos anos, a procura por cortes comerciais e produtos pré-processados tem aumentado devido à preferência do consumidor pela praticidade. Assim, as empresas do setor avícola têm dado atenção especial à qualidade e tamanho dos filés de peito e das pernas de frangos de corte.

$\mathrm{O}$ aumento do tamanho do peito de frango deve-se principalmente ao aumento na espessura do músculo esquelético, especialmente o Pectoralis major

IEvonik Degussa do Brasil Health \& Nutrition, São Paulo, SP, Brasil.

I'Departamento de Zootecnia, Centro de Ciências Agrárias (CCA), Universidade Estadual de Maringá (UEM), Av. Colombo 5790, 87020-900, Maringá, PR, Brasil. E-mail: aemurakami@uem.br.*Autor para correspondência.

IIIDepartamento de Zootecnia, Setor de Ciências Agrárias, Universidade Federal do Paraná (UFPR), Campus Palotina, PR, Brasil.

IVUniversidade Estadual de Mato Grosso do Sul (UEMS), Campus Aquidauana, Aquidauana, MS, Brasil. 
(LUBRITZ, 1997). A formação das fibras do músculo esquelético está completa na eclosão (SMITH, 1963), assim, as fibras diferenciadas terminais são incapazes de sofrer mitoses em circunstâncias normais nos músculos adultos (HALEVY et al., 2000). Dessa forma, o incremento da massa muscular ocorre pela hipertrofia das fibras musculares (BERRI et al. 2007). Durante esse processo, além do incremento protéico das fibras musculares, ocorre o aumento no conteúdo de DNA (CASE et al., 2010), que é atribuído às células precursoras miogênicas presentes no músculo esquelético, denominadas células satélite (MAURO, 1961; FERNANDES et al., 2009).

O processo de maturação das fibras musculares pós-eclosão em frangos de corte é bastante rápido e alterações na ingestão de alimento reduzem a atividade das células satélites e podem influenciar de forma irreversível a maturação das fibras musculares (HALEVY et al., 2000). Assim, o período pós-eclosão é de suma importância no desenvolvimento de frangos de corte, visto que as células satélites são mais ativas neste período (VELLEMAN et al., 2010). Durante o intervalo entre a eclosão e o alojamento, o pintinho consome principalmente os nutrientes do saco vitelínico, embora outros tecidos possam ser utilizados (NOY \& SKLAN, 1999), o que pode reduzir o crescimento das aves, com efeitos a curto e longo prazo. De fato, pintos submetidos a jejum durante os dois primeiros dias de vida não são capazes de recuperar o peso do peito aos 41 dias, comparado aos animais alimentados durante todo o período experimental (HALEVY et al., 2000).

Além do intervalo de alojamento, o balanço adequado dos aminoácidos da dieta pode otimizar a maturação das fibras, com consequente melhora na produção de carne (TESSERAUD et al., 2008). Com o objetivo de evitar o desbalanço nutricional, atualmente, cada aminoácido essencial é expresso com relação a um aminoácido, sendo a lisina a referência utilizada para definir o padrão de proteína ideal (EMMERT \& BAKER, 1997).

A lisina é um dos principais constituintes das proteínas musculares, participando da síntese protéica (ACAR et al., 1991). Segundo TESSERAUD et al. (1996), o músculo P. major é o mais sensível aos níveis de lisina na dieta. $\mathrm{O}$ aumento dos níveis de lisina acima do recomendado está relacionado com o melhor do rendimento da carcaça, especialmente do músculo peitoral, melhoria da conversão alimentar e redução da gordura (MORAN \& BILGILI, 1990).

Assim, o objetivo deste trabalho foi avaliar a influência do intervalo de alojamento e dos níveis de lisina digestível nas dietas iniciais, baseadas no conceito de proteína ideal, sobre o peso do músculo peitoral, diâmetro das fibras musculares esqueléticas do músculo Pectoralis major, relação Proteína:DNA e rendimento da carcaça dos frangos de corte.

\section{MATERIAL E MÉTODOS}

Animais e manejo

O delineamento experimental utilizado foi inteiramente casualizado, em arranjo fatorial $4 \mathrm{x} 2$, sendo quatro intervalos para o alojamento (12, 24, 36 e 48h) e dois níveis de lisina digestível nas dietas iniciais $(1,143$ e $1,267 \%)$, totalizando oito tratamentos, com quatro repetições e 55 aves por unidade experimental.

Para tanto, foram utilizados 1.760 pintos de corte, machos, da linhagem comercial “Cobb500”, com peso médio de 43,5g na eclosão, provenientes de matrizes com 47 semanas de idade. Os animais foram distribuídos aleatoriamente nos tratamentos, pesados e mantidos em caixas de papelão, sem acesso ao alimento ou água, até o respectivo intervalo de alojamento avaliado. Após o alojamento, as aves receberam as dietas experimentais até os 21 dias e uma dieta basal dos 22 aos 42 dias para todos os tratamentos (Tabela 1).

Para a fase inicial (1 a 21 dias, Tabela 1), as dietas foram isoprotéicas, isoenergéticas, isocálcicas, isofosfóricas, isosódicas e isoclorídricas, variando-se os níveis de lisina digestível e, consequentemente, os níveis de metionina+cistina, treonina e triptofano digestível, segundo o padrão de proteína ideal proposto por ROSTAGNO et al. (2000). Durante a fase de crescimento (22 a 42 dias, Tabela 1) utilizou-se o nível 1,045\% de lisina digestível.

Peso do músculo peitoral

Aos 21 e 42 dias de idade, oito aves de cada tratamento foram sacrificadas por deslocamento cervical para extração do peito com osso. As amostras coletadas permaneceram sob refrigeração a $4^{\circ} \mathrm{C}$ por 24 horas post mortem em embalagem plástica de polietileno. Após esse período, foram desossadas e pesadas para avaliação do peso total e do peso do músculo Pectoralis major, considerado comercialmente como Filé de Peito.

Diâmetro das fibras musculares

Aos 21 e 42 dias, duas amostras de tecido muscular da porção superficial do músculo Pectoralis major direito de três aves de cada tratamento foram coletadas para avaliação do diâmetro das fibras musculares esqueléticas estriadas e da relação proteína:DNA. As amostras foram processadas segundo 
a metodologia descrita por FERNANDES et al. (2009). Foram capturadas 15 imagens do tecido muscular por ave (microscópio Olympus Bx 40), com ampliação de 100 vezes, e mensuradas 20 fibras por imagem através do programa Image Pro-Plus 4.1, totalizando 300 fibras musculares por animal em cada idade.

\section{Relação proteína:DNA}

A quantidade de DNA no músculo peitoral foi avaliada após extração de DNA de 50mg de tecido muscular utilizando-se o kit Dneasy Tissue ${ }^{\circledR}$ da QIAGEN, para isolamento de DNA genômico. Depois de extraída, a quantidade de DNA foi mensurada por espectrofotometria em 260 e $280 \mathrm{~nm}\left(\mathrm{~A}_{260}\right.$ e $\left.\mathrm{A}_{280}\right)$. Os valores foram apresentados por $\mathrm{mg}$ de tecido.

Para determinar a concentração de proteínas solúveis, as amostras foram descongeladas, trituradas e dissolvidas em solução tampão de lise. A solução $\left(1 \%, \mathrm{~g} \mathrm{v}^{-1}\right)$ foi centrifugada por 15 minutos a $13.000 \mathrm{~g} \mathrm{e}$ as proteínas solúveis foram determinadas usando o método descrito por BRADFORD (1976).

Rendimento de carcaça

O rendimento de carcaça foi determinado em três aves por unidade experimental aos 43 dias. As aves foram submetidas a seis horas de jejum e posteriormente atordoadas com eletricidade e sacrificadas por sangria. No cálculo de rendimento de carcaça, foi considerado o peso da carcaça eviscerada, sem pés, cabeça e gordura abdominal, em relação ao peso vivo, obtido individualmente antes do abate das aves. Em relação aos cortes comerciais, foram avaliados os rendimentos do peito inteiro e das pernas (coxa e sobrecoxa) com pele e ossos em relação ao peso da carcaça eviscerada.

Tabela 1 - Composição percentual e calculada das dietas experimentais dos frangos de corte nos períodos inicial (1 a 21 dias) e de crescimento (22 a 42 dias).

\begin{tabular}{|c|c|c|c|}
\hline Ingredientes, \% & \multicolumn{2}{|c|}{-----------------------------------Inicial-------------------------------- } & Crescimento \\
\hline Milho, grão & 67,850 & 68,570 & 73,100 \\
\hline Farelo de soja $45 \%$ & 27,700 & 26,800 & 22,200 \\
\hline Fosfato bicálcico & 1,860 & 1,860 & 1,650 \\
\hline Calcário & 1,020 & 1,020 & 0,960 \\
\hline Óleo de soja & 0,210 & ----- & 0,720 \\
\hline L-Lisina HCL, 78\% & 0,393 & 0,581 & 0,433 \\
\hline DL-Metionina, 98\% & 0,287 & 0,386 & 0,259 \\
\hline L-Treonina, 98\% & 0,060 & 0,155 & 0,052 \\
\hline L-Triptofano, $98 \%$ & ---- & 0,030 & 0,026 \\
\hline Suplemento mineral e vitamínico ${ }^{1,2,3}$ & 0,150 & 0,150 & 0,200 \\
\hline Sal comum & 0,460 & 0,460 & 0,390 \\
\hline Antioxidante & 0,010 & 0,010 & 0,010 \\
\hline Total & 100,000 & 100,022 & 100,000 \\
\hline Energia metabolizável, kcal kg-1 & $3.000,000$ & $3.000,000$ & $3.100,000$ \\
\hline Proteína bruta, \% & 19,000 & 19,000 & 17,000 \\
\hline Cálcio, \% & 0,960 & 0,960 & 0,875 \\
\hline Fósforo disponível, \% & 0,450 & 0,450 & 0,406 \\
\hline Lisina digestível, \% & 1,143 & 1,267 & 1,045 \\
\hline Metionina +Cistina digestível, \% & 0,812 & 0,900 & 0,742 \\
\hline Relação Met + Cis/Lisina & 71 & 71 & 71 \\
\hline Triptofano digestível, \% & 0,199 & 0,220 & 0,193 \\
\hline Triptofano/Lisina & 17 & 17 & 18 \\
\hline Treonina digestível, \% & 0,675 & 0,748 & 0,596 \\
\hline Treonina/Lisina & 59 & 59 & 57 \\
\hline Sódio, \% & 0,222 & 0,222 & 0,192 \\
\hline Cloro, \% & 0,311 & 0,312 & 0,272 \\
\hline
\end{tabular}

${ }^{1}$ Mistura Vitamínica Inicial (Conteúdo por kg de suplemento): Vit. A 7.000.000,000UI; Vit. D3 2.200.000,000UI; Vit.E 11.000,000mg; Vit.

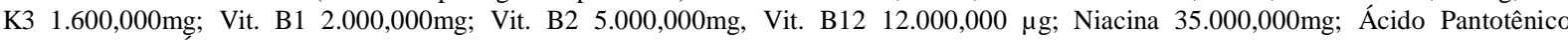
13.000,000mg; Ácido Fólico 800,000mg; Antioxidante 100.000,000; Veículo q.s.p. 1.000,000g.

${ }^{2}$ Mistura Vitamínica de Crescimento (Conteúdo por kg de suplemento): Vit. A 6.000.000,000UI; Vit. D3 2.000.000,000UI; Vit.E

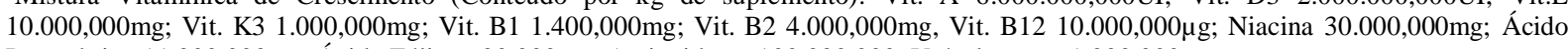
Pantotênico 11.000,000mg; Ácido Fólico 600,000mg; Antioxidante 100.000,000; Veículo q.s.p. 1.000,000g.

${ }^{3}$ Mistura mineral (Conteúdo por kg de suplemento): Ferro 10.000,000mg; Cobre 16.000,000mg; Iodo 2.400,000mg; Zinco 100.000,000mg; Manganês 140.000,000mg; Selênio 400mg; Veículo q.s.p. 1.000,000g. 
Análise estatística

A análise estatística dos dados foi efetuada utilizando-se o programa estatístico SAEG (1998). Após a análise de variância, os graus de liberdade referentes aos intervalos para o alojamento foram desdobrados em polinômios e analisados através de regressão polinomial.

\section{RESULTADOS E DISCUSSÃO}

De acordo com os resultados deste estudo, não houve interação significativa $(\mathrm{P}>0,05)$ entre os níveis de lisina e os intervalos para alojamento sobre todos os parâmetros avaliados aos 21 e 42 dias de idade (Tabelas 2, 3 e 4). O peso do peito desossado e peso do filé do peito aos 21 dias e peso vivo aos 43 dias foram afetados pelos níveis de lisina, com melhora desses parâmetros com o nível de $1,143 \%$ de lisina digestível $(\mathrm{P} \leq 0,05$, Tabelas 2 e 4). De fato, em animais alimentados com nível de lisina digestível abaixo do recomendado (0.82\%), nos 3 primeiros dias de vida, ocorre um aumento na atividade mitótica das células satélites (POPHAL et al., 2004), proporcionando, consequentemente, aumento no tamanho do peito.

No entanto, a atividade mitótica das células satélites não influenciou no aumento muscular, visto que não houve diferença $(\mathrm{P}>0,05)$ na relação Proteína:DNA das fibras musculares (Tabela 3). De acordo com HALEVY et al. (2000), 95\% do DNA das fibras musculares é derivado de células satélite e a adição de novos núcleos provenientes dessas células é necessária para aumento na massa muscular e produção de carne.

Apesar dos resultados evidenciarem que a utilização de 1,143\% de lisina digestível, em relação a $1,267 \%$, melhorou o peso do peito e dos filés aos 21 dias, a utilização de níveis acima do recomendado para a obtenção do ótimo desempenho dos frangos tem sido associada principalmente com a maximização no rendimento do músculo peitoral (MORAN \& BILGILI, 1990). Possivelmente, os piores resultados obtidos para $1,267 \%$ de lisina podem estar relacionados ao nível de 19\% de proteína no período inicial. Este nível pode ter sido insuficiente para fornecer a quantidade de nitrogênio necessária para a síntese de aminoácidos não essenciais na fase inicial.

Além disso, nas dietas formuladas no conceito de proteína ideal, nas quais cada aminoácido essencial é expresso com relação à lisina, o aumento nos níveis de lisina acarreta aumento nos níveis de metionina+cistina, treonina e triptofano. Este aumento pode levar a um desequilíbrio entre os aminoácidos essenciais e não essenciais, o que pode ter resultado na piora no peso do peito e dos filés nesses animais. Em situações de desequilíbrio de aminoácidos, estes

Tabela 2 - Influência do intervalo para o alojamento (IA) e dos níveis de lisina digestível, em dietas baseadas no conceito de proteína ideal, sobre o peso do peito desossado e peso médio dos filés do peito (direito + esquerdo) dos frangos de corte aos 21 e 42 dias.

\begin{tabular}{|c|c|c|c|c|}
\hline \multirow{2}{*}{ Variáveis } & \multirow[b]{2}{*}{ 21d } & \multirow[b]{2}{*}{$42 d$} & \multirow[b]{2}{*}{$21 d$} & \multirow[b]{2}{*}{$42 d$} \\
\hline & & & & \\
\hline 12 & 106,00 & 440,21 & 29,97 & 57,50 \\
\hline 24 & 102,10 & 438,49 & 28,72 & 57,99 \\
\hline 36 & 98,20 & 418,02 & 27,47 & 57,96 \\
\hline 48 & 94,30 & 438,36 & 26,22 & 57,88 \\
\hline 1,143 & 102,55 & 444,62 & 29,24 & 57,85 \\
\hline 1,267 & 97,13 & 422,92 & 26,95 & 57,82 \\
\hline Média & $99,84 b$ & $433,62 c$ & 28,09 & 57,84 \\
\hline CV (\%) & 7,69 & 10,34 & 9,74 & 4,07 \\
\hline Níveis de lisina & $*$ & NS & $*$ & NS \\
\hline Intervalo de alojamento & Linear $^{1}$ & NS & Linear $^{2}$ & NS \\
\hline Interação & NS & NS & NS & NS \\
\hline $\mathrm{R} 2$ & 0,23 & ------ & 0,21 & ------ \\
\hline
\end{tabular}

* Significativo $(\mathrm{P}<0,05)$; NS = Não Significativo; 1. Y=109,901-0,325091X;

2. $Y=31,2247-0,104246 X$. 
Tabela 3 - Influência do intervalo para o alojamento (IA) e dos níveis de lisina digestível, em dietas baseadas no conceito de proteína ideal, sobre o diâmetro das fibras musculares esqueléticas e relação Proteína:DNA do músculo Pectoralis major dos frangos de corte aos 21 e 42 dias.

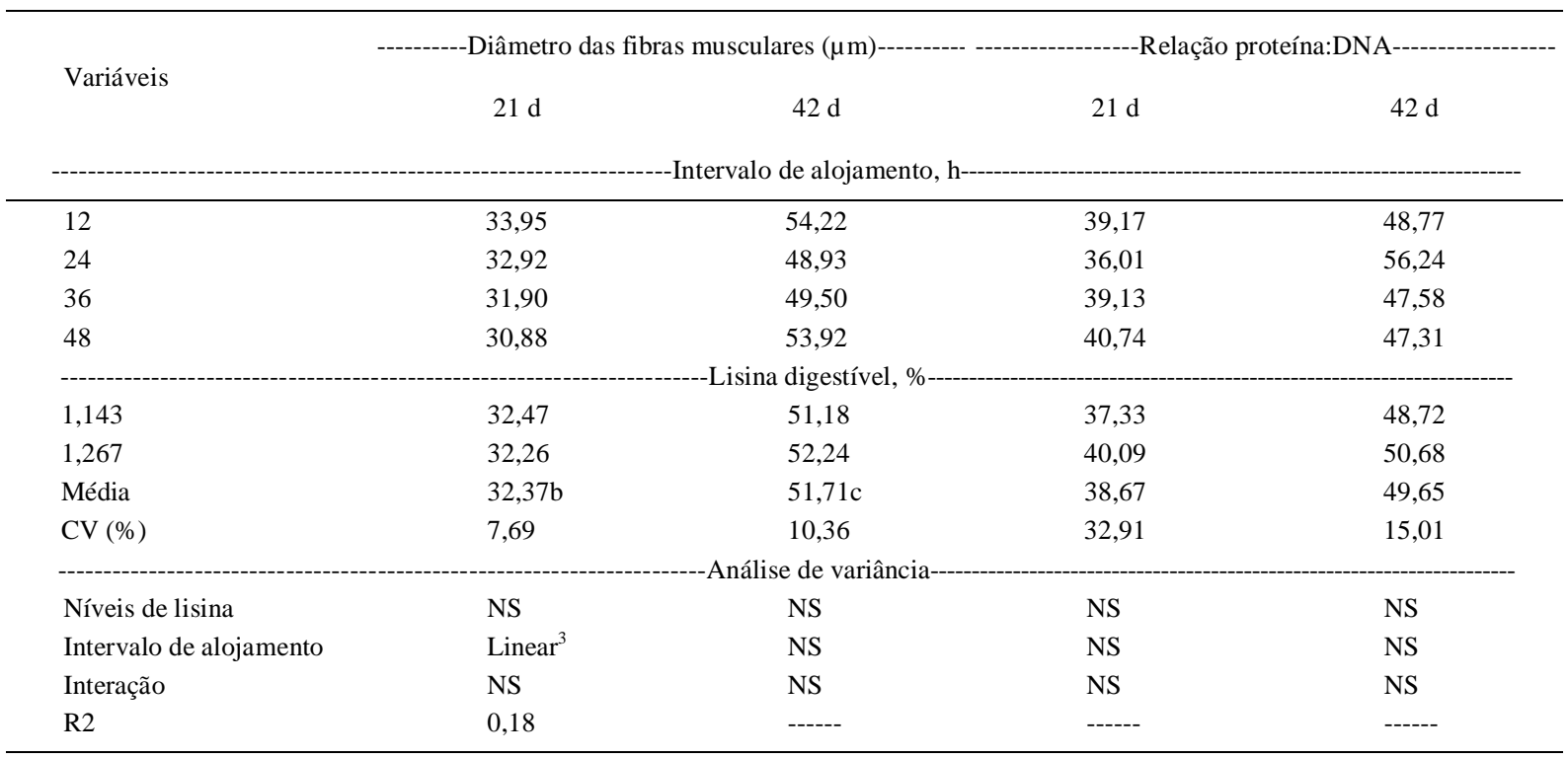

NS = Não Significativo; 3.Y=34,9737-0,0853935X;

são convertidos em lipídios e depositados no tecido adiposo ou catabolizado e excretados na forma de ácido úrico nas aves. Assim, a energia que poderia ser utilizada para deposição de tecidos é desviada para excreção de nitrogênio (COSTA et al., 2001).

Além do nível de proteína e do balanço de aminoácidos, o intervalo para o alojamento é muito importante no desempenho dos animais. Durante a primeira semana de vida, ocorre a proliferação e diferenciação das células satélite e, a partir desse período, ocorre uma diminuição drástica na população de células satélites (HALEVY et al., 2000). Assim, períodos prolongados entre a eclosão e o alojamento acarretam perdas no desempenho a longo prazo, visto que jejum de 48 horas após a eclosão diminui o peso corporal, o desenvolvimento do trato gastrointestinal e a proliferação das células satélites (HALEVY et al., 2000; NOY et al., 2001). De fato, neste estudo, os maiores intervalos para alojamento comprometeram o peso do peito desossado, peso do filé de peito, diâmetro das fibras musculares aos 21 dias, bem como o peso vivo, peso da carcaça e peso das pernas no abate aos 43 dias, os quais decresceram linearmente de acordo com os maiores períodos para alojamento dos animais $(P \leq 0,05$, Tabelas 2,3 e 4$)$.

É interessante notar que o padrão de resposta do peso do peito e diâmetro das fibras musculares em relação aos intervalos de alojamento foi similar, com resposta linear decrescente aos 21 dias. Essa resposta é esperada visto que o peso do peito está associado ao diâmetro das fibras musculares, com o desenvolvimento muscular sendo dependente da variação no diâmetro e comprimento das fibras musculares (CASE et al., 2010). Além disso, a diminuição na relação proteína:DNA aos 7 dias está associada à redução no peso do peito, com o desenvolvimento muscular variando de acordo com o conteúdo de proteína e de DNA, atribuído às células satélites (MAURO, 1961; FERNANDES et al., 2009).

O maior intervalo para alojamento influenciou de forma negativa no desenvolvimento dos músculos peitorais dos frangos de corte até aos 21 dias ( $\mathrm{P} \geq 0,05$, Tabela 2). Entretanto, aos 42 dias de idade, este parâmetro foi similar entre os diferentes períodos para o alojamento ( $\mathrm{P} \geq 0,05$, Tabela 4). Esse resultado discorda do obtido por HALEVY et al. (2000), os quais evidenciaram que os pintos submetidos ao jejum inicial de até 48 horas não são capazes de recuperar o peso do peito aos 41 dias. Estes autores atribuíram este efeito ao menor índice de proliferação das células satélites em resposta ao jejum logo após a eclosão. A recuperação do peso dos músculos peitorais e no diâmetro das fibras musculares aos 42 dias, neste estudo, pode estar relacionada ao aumento 
Tabela 4 - Influência do intervalo para o alojamento (IA) e dos níveis de lisina digestível, em dietas baseadas no conceito de proteína ideal, sobre o peso vivo e rendimento de carcaça e de cortes (peito e pernas) dos frangos de corte aos 43 dias.

\begin{tabular}{|c|c|c|c|c|c|c|c|}
\hline \multirow{2}{*}{ Variáveis } & \multicolumn{4}{|c|}{ 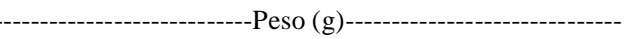 } & \multicolumn{3}{|c|}{ 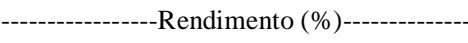 } \\
\hline & Vivo & Carcaça & Peito & Pernas & Carcaça & Peito & Pernas \\
\hline 12 & 2789,91 & 1929,58 & 681,91 & 618,36 & 69,19 & 35,18 & 32,01 \\
\hline 24 & 2734,78 & 1882,42 & 665,08 & 603,79 & 68,81 & 34,51 & 32,20 \\
\hline 36 & 2679,65 & 1835,27 & 635,33 & 589,22 & 68,33 & 35,75 & 31,96 \\
\hline 48 & 2634,51 & 1788,12 & 628,99 & 574,64 & 68,22 & 35,26 & 32,29 \\
\hline 1,143 & 2709,75 & 1863,92 & $\begin{array}{r}\text { sina dig } \\
657,10\end{array}$ & $\begin{array}{l}\text { \%------- } \\
\text { 598,34 }\end{array}$ & 68,70 & 35,45 & 32,11 \\
\hline 1,267 & 2640,38 & 1852,42 & 650,66 & 594,24 & 68,57 & 34,90 & 32,11 \\
\hline Média & 2675,07 & 1858,17 & 653,88 & 596,29 & 68,64 & 35,18 & 32,11 \\
\hline CV (\%) & 5,02 & 6,50 & 9,14 & 7,33 & 2,26 & 5,61 & 4,93 \\
\hline Níveis de lisina & $*$ & NS & NS & NS & NS & NS & NS \\
\hline Intervalo de alojamento & Linear $^{4}$ & Linear $^{5}$ & NS & Linear $^{6}$ & NS & NS & NS \\
\hline Interação & NS & NS & NS & NS & NS & NS & NS \\
\hline $\mathrm{R} 2$ & 0,26 & 0,16 & ---- & 0,12 & ---- & ---- & ---- \\
\hline
\end{tabular}

* Significativo $(\mathrm{P}<0,05)$; NS = Não Significativo; 4. $\mathrm{Y}=2862,04-6,23264 \mathrm{X}$;

5. $\mathrm{Y}=1976,73-3,92942 \mathrm{X}$; 6. $\mathrm{Y}=632,927-1,21422 \mathrm{X}$.

“compensatório” observado para a altura dos vilos no duodeno aos 21 dias, bem como, ao maior consumo de ração deste período adiante, a partir dos intervalos para o alojamento de aproximadamente 33 horas (FRANCO et al., 2006).

Apesar da recuperação no peso do peito na idade de abate, o peso vivo e o peso da carcaça diminuiu linearmente com o aumento do intervalo de alojamento. Esta resposta pode ser resultado da diminuição linear do peso das pernas, sugerindo que esses membros possam ser mais susceptíveis ao efeito negativo do prolongamento do intervalo para o alojamento do que os músculos peitorais. Essa diferença poderia estar associada aos tipos e às frequências das fibras que os compõem, bem como as suas diferentes taxas de crescimento.

\section{CONCLUSÃO}

O diâmetro das fibras musculares do músculo Pectoralis major e a relação proteína:DNA não são influenciados pelos níveis de lisina estudados, contudo, o fornecimento da dieta contendo $1,143 \%$ de lisina digestível, baseada no conceito de proteína ideal, durante a fase inicial, proporciona o maior peso dos músculos peitorais aos 21dias, bem como o maior peso vivo dos frangos de corte aos 43 dias, independentemente do intervalo para o alojamento. Pintos de corte alojados e alimentados até 12 horas após a eclosão obtêm maiores diâmetro das fibras musculares esqueléticas e peso dos músculos peitorais até aos 21 dias, bem como o peso da carcaça e das pernas (coxa+sobrecoxa) aos 43 dias.

\section{AGRADECIMENTO}

Ao Conselho Nacional de Desenvolvimento Científico e Tecnológico (CNPq).

\section{COMITÊDE ÉTICA E BIOSSEGURANÇA}

Este projeto foi aprovado pelo Comitê de Conduta Ética no Uso de Animais em Experimentação (CEAE 009/ 2006) da Universidade Estadual de Maringá, Maringá, Paraná.

\section{REFERÊNCIAS}

ACAR, N. et al. Live performance and carcass yield of male broilers from two commercial strain crosses receiving rations containing lysine below and above the established requirement between six and eight weeks of age. Poultry Science, v.70, p.315-321, 1991. Disponível em: <http://ps.fass.org/content/ 70/11/2315.short>. Acesso em: 04 maio 2012. doi: 10.3382/ ps.0702315.

BERRI, C. et al. Consequence of muscle hypertrophy on characteristics of Pectoralis major muscle and breast meat quality of broiler chickens. Journal of Animal Science, v.85, p.2005-2011, 2007. Disponível em: <http://jas.fass.org/

Ciência Rural, v.42, n.9, set, 2012. 
content/85/8/2005.long>. Acesso em: 04 maio, 2012. doi: 10.2527/jas.2006-398.

BRADFORD, M.M. A rapid and sensitive method for the quantitation of microgram quantities of protein utilizing the principle of protein-dye binding. Analytical Biochemistry, v.72, p.248-254, 1976. Disponível em: <http://www.sciencedirect.com/ science/article/pii/0003269776905273>. Acesso em: 04 maio, 2012. doi: 10.1016/0003-2697(76)90527-3.

CASE, L.A. et al. Factors affecting breast meat yield in turkeys. World Poultry Science Journal, v.66, p.189-202, 2010. Disponível em: <http://journals.cambridge.org/download.php?file=\%2 FWPS\%2FWPS66_02\%2FS 0043933910000255 a.pdf\& code $=$ dcbe81636de42955a239898b8d35813a>. Acesso em: 04 maio, 2012. doi: 10.1017/S0043933910000255.

COSTA, F.G.P. et al. Níveis dietéticos de proteína bruta para frangos de corte de 1 a 21 e 22 a 42 dias de idade. Revista Brasileira de Zootecnia, v.30, p.1498-1505, 2001. Disponível em: <http:// www.scielo.br/scielo.php?script $=$ sci_arttext\&pid $=$ S151635982001000600017\&lng=en\&nrm=iso>. Acesso em: 04 maio, 2012. doi: 10.1590/S1516-35982001000600017.

EMMERT, J.L.; BACKER, D.H. Use of the ideal protein concept for precision formulation of amino acid levels in broiler diets. Journal of Applied Poultry Research, v.6, p.462-470, 1997. Disponível em: <http://japr.fass.org/content/6/4/462.short>. Acesso em: 04 maio, 2012.

FERNANDES, J.I.M. et al. Effect of arginine on the development of the pectoralis muscle and the diameter and the protein:deoxyribonucleic acid rate of its skeletal myofibers in broilers. Poultry Science, v.88, p.1399-1406, 2009. Disponível em: <http://ps.fass.org/content/88/7/1399.long>. Acesso em: 04 maio, 2012. doi: 10.3382/ps.2008-00214.

FRANCO, J.R.G. et al. Influence of delayed placement and dietary lysine levels on small intestine morphometrics and performance of broilers. Revista Brasileira de Ciência Avícola, v.8, p.233-241, 2006. Disponível em: <http://www.scielo.br/scielo.php?pid=S1516 635X2006000400006\&script=sci_arttext\&tlng=pt $>$. Acesso em: 04 maio, 2012. doi: 10.1590/S1516-635X2006000400006.

HALEVY, O. et al. Early posthatch starvation decreases satellite cell proliferation and skeletal muscle growth in chicks. Journal of Nutrition, v.130, p.858-864, 2000. Disponível em: <http:// jn.nutrition.org/content/130/4/858.long>. Acesso em: 04 maio, 2012.

LUBRITZ, S.L. A statistical model for white meat yield in broiler. Journal of Applied Poultry Research, v.6, p.253259, 1997. Disponível em: <http://japr.fass.org/content/6/3/ 253.short>. Acesso em: 04 maio, 2012.

MAURO, A. Satellite cells of skeletal muscle fibers. Journal of Biophysical and Biochemistry Cytology, v.9, p.493-
495, 1961. Disponível em: <http://jcb.rupress.org/content/9/ 2/493.full.pdf>. Acesso em: 04 maio, 2012.

MORAN, E.T.; BILGILI, S.F. Processing losses, carcass quality, and meat yields of broiler chickens receiving diets marginally deficient to adequate in lysine prior to marketing. Poultry Science, v.69, p.702-710, 1990. Disponível em: <http:// ps.fass.org/content/69/4/702.abstract>. Acesso em: 04 maio, 2012. doi: 10.3382/ps.0690702.

NOY, Y.; SKLAN, D. Different types of early feeding and performance in chicks and poults. Journal of Applied Poultry Research, v.8, p.16-24, 1999. Disponível em: <http:// japr.fass.org/content/8/1/16.short>. Acesso em: 04 maio, 2012..

NOY, Y. et al. The effect of early feeding on growth and small intestinal development in the posthatch poult. Poultry Science, v.80, p.912-919, 2001. Disponível em: <http:// ps.fass.org/content/80/7/912.short>. Acesso em: 04 maio, 2012.

POPHAL, S. et al. Satellite cell mitotic activity of broilers fed differing levels of lysine. International Journal of Poultry Science, v.3, p.758-763, 2004. Disponível em: <http:// www.pjbs.org/ijps/fin290.pdf>. Acesso em: 04 maio, 2012.

ROSTAGNO, H.S. et al. Tabelas brasileiras para aves e suínos; composição de alimentos e exigências nutricionais. Viçosa: Universidade Federal de Viçosa, 2000. 141p.

SAEG - Sistema para análises estatísticas e genéticas: versão 8.0. Viçosa: Fundação Arthur Bernardes, 1998. 150p.

SMITH, J.H. Relation of body size to muscle cell size and number in the chicken. Poultry Science, v.42, p.283-290, 1963. Disponível em: <http://ps.fass.org/content/42/2/ 283.short>. Acesso em: 04 maio, 2012. doi: 10.3382/ ps.0420283.

TESSERAUD, S. et al. Relative responses of protein turnover in three skeletal muscles to dietary lysine deficiency in chicks. British Poultry Science, v.37, p.641-650, 1996. Disponível em: <http:/ /www.tandfonline.com/doi/abs/10.1080/00071669608417893>. Acesso em: 04 maio, 2012. doi: 10.1080/00071669608417893.

TESSERAUD, S. et al. Daily variations in dietary lysine content alter the expression of genes related to proteolysis in chicken Pectoralis major muscle. Journal of Nutrition, v.139, p.3843, 2008. Disponível em: <http://jn.nutrition.org/content/139/ 1/38.short $>$. Acesso em: 04 maio, 2012. doi: 10.3945/ jn.108.095752.

VELLEMAN, S.G. et al. Changes in satellite cell proliferation and differentiation during turkey muscle development. Poultry Science, v.89, p.709-715, 2010. Disponível em: <http:// ps.fass.org/content/89/4/709.short>. Acesso em: 04 maio, 2012. doi: $10.3382 /$ ps.2009-00467. 